Raw wool may contain fifty per cent of its weight of grease, suint, dirt and vegetable matter. Its clean. ing is, therefore, an intricate process, and was the subject of two papers from the Wool Industries Research Association. Some of the fundamental principles of washing raw wool with solutions of soap and soda were dealt with by Dr. H. Phillips, who showed that the $p \mathrm{H}$ values of the detergent solutions used influence their wetting and emulsifying powers, and the stability of the emulsions which they form. Variations in the relative proportions of the different impurities in raw wool, caused by variations in the health of the sheep and the climatic conditions, have to be met by alterations in the washing process, which can only be foreseen when the process is under scientific control. Inherent weaknesses in the process are the effect of the alkali used on the wool and the incomplete removal of vegetable matter.

Dr. S. Townend described the frosted wool process, recently developed in the United States, by which it is elaimed that large quantities of vegetable matter and grease can be removed from raw wool without subjecting it to alkaline solutions. The wool is cooled to $-40^{\circ} \mathrm{F}$., and the frozen grease and vegetable matter are broken up and removed by mechanical treatment. The process removes more vegetable matter than the normal washing process, but the finer qualities of wool still require carbonising after treatment. The grease content of the wool cleaned by this process is also relatively high, and for certain purposes the wool has to be washed with soap and soda.

\title{
Chemical Engineering Congress of the World Power Conference
}

$\mathrm{H}$ R.H. THE DUKE OF KENT, in opening on Monday, June 22, the First International Chemical Engineering Congress at the Central Hall, Westminster, and welcoming delegates and members from thirty-seven countries, said: "Proud as each country is of the achievements of her great scientists and inventors, their work once done becomes international and contributes to the well-being and happiness of every race". The Right Hon. Viscount Leverhulme, in his presidential address which followed, dealt with the subject of chemical engineering and stated that the conception of holding an international congress of this kind was due to the late Sir Frederic Nathan, and that the development of that ideal into the present meeting was brought about by the World Power Conference.

About 120 papers from fifteen different countries were presented for discussion, whilst the membership numbered 850 , comprising about 350 representatives from thirty-six overseas countries.

Two technical sessions were held before lunch and two in the afternoon on Tuesday, June 23, and Friday, June 26, but as visits to colleges, research institutions and works in and around London had been arranged for Wednesday afternoon and Thursday afternoon, the technical sessions on these days were limited to the forenoon.

Since chemical plant may have to resist corrosive conditions and may have to withstand high tem. peratures and/or high pressures, both the material of which it is constructed and the method of fabrication are important factors to the chemical engineer. It was therefore not surprising that the papers and discussions at the first two sessions on Tuesday morning were devoted to materials of construction. At the first of these, eight papars were presented dealing with ferrous metals and their alloys designed to resist heat, rust and acid corrosion, the forging of autoclaves and vessels for withstanding liquids at high temperatures and pressures. Nor was cast iron omitted, for included in this section were papers showing the result of recent research work on this material and its application in chemical industry, as well as others on the prevention of corrosion in underground pipe lines made of ferrous metals. The following session covered a much wider field since it contained papers on refractory materials, stoneware, plastics, rubber and such lesser known fibres as jute, coir, and sisal, as well as non-ferrous metals and their alloys, and their application in the construction of chemical plant.

Separation in the chemical industry is such a wide subject that at the third session, after lunch, the papers ranged from the theory of coal-washing through the recovery of benzol and the removal of carbon monoxide from town's gas to the production and treatment of road tars and to problems connected with the distillation of absolute alcohol, fractionation of heavy oils, modern cracking pro. cesses and graphical calculations relating to plate columns. Included in this section were other papers on filtration, recent developments in evaporation, crystallization, solvent extraction and drying.

The fourth session, which followed immediately, contained several papers relating to some interesting aspects of size reduction, among which was one describing a plant wherein low-grade fuel such as lignite can be pulverized and fired into the furnace of a boiler in one process, the boiler operating at a very high efficiency.

Another group of papers in this session considered electro-metallurgical and electro-chemical industries, as well as the electrolytic treatment of water for the prevention of corrosion and boiler scale and methods of removing small quantities of iron from soluble alumin. ium salts, the pasteurization of liquids, anodic oxida. tion of aluminium and are welding of low carbon steels.

At the first session on Wednesday morning, the subject under discussion was destructive distillation, in which in addition to a paper on the underground gassification of coal, there was a number of papers on the problems connected with the manufacture of water gas and town's gas from lignite and similar fuels, as well as several papers on the various aspects of the development which has taken place in the gas in. dustry in various parts of the world.

With the rapid growth of large industrial units, the disposal of waste material, whether solid, liquid or gaseous, has become a pertinent and pressing problem to the chemical engineer. It formed the subject of several papers at the next session. Coupled with this series were other papers which showed the recent developments which have taken place in the preparation and treatment of lubricating oils. 
Within comparatively recent times, considerable attention has been directed towards the use of high pressures in the synthesis of organic compounds, the hydrogenation of tar and tar distillates and gaseous liquid phase reactions. The first session on Thursday morning was devoted to this subject. Included with this group of papers was one on the use of high vacua.

Few chemical engineers escape the problem of considering the transmission of heat to or the removal of heat from the product at one or more stages in the course of its manufacture. The importance of this subject therefore demanded the attention of the members during the second session on Thursday morning, when papers dealing with the evaporation of solutions liable to be affected by high temperatures, and the use of waste heat for low-temperature evaporation as well as methods by which waste heat may be recovered from intermittent sources, were under discussion.

The attendance and discussion which followed the report upon the papers on Friday morning dealing with the training of a chemical engineer indicated how this subject has been claiming the attention of both industrialists and teachers in America, Austria, Canada, France, Germany, Great Britain, Japan and the U.S.S.R.

In the session which followed were papers from Germany, Great Britain and the United States of America on administration, safety and welfare, and the statistical duties which fall to the lot of the chemical engineer in industry. These papers show how the countries concerned are taking precautionary measures to reduce accidents and occupational risks attendant upon chemical industry, and the factors which influence the choice of site for a works and the cost of the product.

Trend of development was the title allotted to the first session on Friday afternoon, at which papers were presented on a variety of subjects in which amongst others are those relating to water treatment and softening, fumigation, developments in the sulphuric acid industry and the production of concentrated fertilizers from poor phosphates. Although the papers in this group deal with many subjects, their importance to the technical worker cannot be denied, since they consider problems arising in many industries.

The organization of research stations both of a public and private character and the part which fundamental research must play in industrial organizations were the subjects of some of the papers presented at the last session, which also included other papers on rapid methods of determining the standard of the product, the standardization of chemical apparatus and its future development, as well as a number of other aspects of interest to the chemical engineer.

Sir Harold Hartley, chairman of the International Executive Council of the World Power Conference, presided on Saturday morning at the closing meeting of the Congress, at which various reports were presented. Thanks were also tendered by numerous speakers to the various committees and officers, and a striking tribute not only to the success but also to the utility of the Congress was given when it was announced that an invitation had been received from the German National Committee to hold a second International Congress on Chemical Engineering in Berlin in 1940.

\section{Oceanic Macroplankton of the Dana Expeditions*}

$\mathrm{D}^{\mathrm{R}}$ R. P. JESPERSEN has compared the amount of macroplankton in the various waters investigated by the Carlsberg Foundation's Oceanographical Expedition round the world in 1928-30. Volume determinations were made of 2231 pelagic hauls, distributed in eight regions-North Atlantic and Caribbean Sea, Pacific and Tasmanian Sea, Indo-Malayan region, waters west of Sumatra, Indian Ocean, South Atlantic, Straits of Gibraltar and adjacent waters, and the Mediterranean.

The paper deals solely with the purely quantitative side of the macroplankton as a whole, the only exception being a determination of the fish and fish fry of the different water layers in the regions of the Pacific : otherwise only occasional notice is taken of what organisms may be dominant-so far as volume is concerned-in the composition of the plankton. It is usually the salps which are thus noted, sometimes siphonophores, Sagitta, euphausiids and decapods.

A comparison of the microplankton on the two sides of the Panama Isthmus shows a very great difference. Thus in the upper water layers $(50-100$ metres wire) the quantity is greater in the Caribbean

* The Carlsberg Foundation's Oceanographical Expedition round the World, 1928-30, and previous Dana-Expeditions. Dana-Report plankton in different Oceanic Regions $\mathrm{By} \mathrm{P}$. Jespersen $\mathrm{Pp}$. 44 (Copenhagen $\quad$ C. A. Reitzel's Forlag; London: Oxford University Press, 1935. 7.
Sea, but in all deeper hauls the volumes are very much greater in the Gulf of Panama. It is shown that in layers corresponding to hauls with 300-600 metres wire the amount of macroplankton in the Gulf of Panama is about twice the amount in the Caribbean Sea, and in depths corresponding to hauls with 1,000-3,000 metres wire the quantities of plankton are six to eight times larger in the Gulf of Panama than in the Caribbean Sea. The remarkably rich plankton fauna in the deeper waters of the Gulf of Panama is of peculiar interest, as nowhere else in the areas of the Pacific, Indian Ocean or the South Atlantic investigated is anything like such large quantities met with. It is only in the North Atlantic at about $30^{\circ} \mathrm{N}$. that corresponding quantities of plankton are found in the deeper layers.

It is characteristic of the plankton fauna of the Gulf of Panama that it is considerably richer in the deeper than in the surface layers, a condition quite unique, since at all other places in the regions investigated the quantities of plankton are greatest in the upper layers. It may be said that, on the whole, the quantity of macroplankton in the deeper layers (hauls with at least 1,000 metres wire) is comparatively small and fairly uniform in most of the tropical and temperate oceanic regions. The one exception is the Gulf of Panama, where we find a remarkably large quantity of plankton in the deeper layers. 